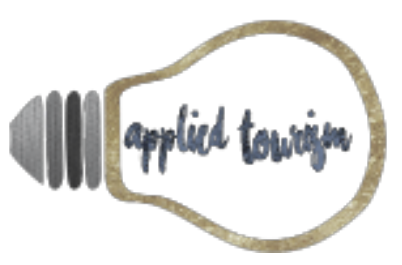

Volume 3, número 3, 2018, p. 13- 36

\title{
O TURISMO COLABORATIVO COMO FERRAMENTA DE INTERCÂMBIO: Estudo de Caso em uma Universidade Brasileira.
}

Recebido: 26 de fevereiro, 2018

Aprovado: 07 de março, 2018

\section{RESUMO}

Este trabalho buscou analisar o que pensam os alunos da UFPel sobre o turismo colaborativo como ferramenta de intercâmbio, através da trajetória metodológica de um estudo de caso de caráter descritivo e exploratório, qualiquantitativo, utilizando como instrumento de pesquisa a aplicação de um questionário, com um total de 113 respondentes. O objetivo foi investigar o que sabem, as opiniões e os anseios dos alunos da UFPel, frente as plataformas "work exchange" e a temática do intercâmbio. A partir da análise dos dados obtidos nota-se que a maioria nunca realizou intercâmbio, porém observou-se o desejo de vivenciar esta experiência. Os dados obtidos indicaram que 90\% não tem conhecimento sobre nenhuma plataforma que promova o "work exchange". Conclui-se que é necessária uma maior divulgação sobre turismo colaborativo e suas relações com intercâmbio, a fim de possibilitar mais opções aos que tem interesse em viajar e também ampliar os estudos sobre o tema.

Palavras-chaves: Turismo Colaborativo. Intercâmbio. "Work exchange" 


\section{INTRODUÇÃO}

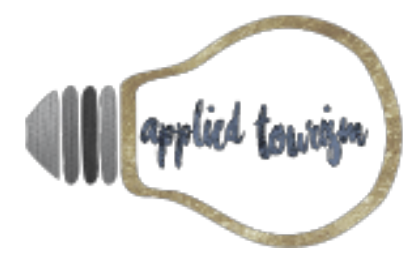

Volume 3, número 3, 2018, p. 13- 36

O presente estudo trabalhou com as seguintes temáticas: turismo colaborativo, intercâmbio e suas implicações em relação as plataformas Work Exchange. Esta pesquisa objetivou compreender o que sabem, as opiniões e os anseios dos alunos da Universidade Federal de Pelotas frente aos referidos assuntos.

O conceito de turismo colaborativo teve início nos Estados Unidos da América e em alguns países da Europa e ele pode ser entendido como a troca do custo da viagem pela prestação de algum serviço oferecido pelo viajante. Tal conceito foi baseado em outro conceito mais abrangente que é a chamada economia colaborativa.

A economia colaborativa abrange modelos como o financiamento, a aprendizagem, a produção e o consumo, os quais permitem o contato direto entre os indivíduos, através de plataformas de interação, promovendo assim uma descentralização dos meios convencionais de acesso, criando desta forma novos mercados, onde não há necessariamente envolvimento do dinheiro na sua forma clássica (STOKES et al, 2014). Bostman e Rogers (2011), que descrevem os estilos de vida colaborativos, onde observa-se o compartilhamento e a troca de ativos intangíveis, como tempo, espaço e habilidades, como a hospedagem colaborativa, onde os indivíduos podem utilizar o modelo Work Exchange.

O termo intercâmbio está diretamente ligado ao turismo, que é uma das temáticas de interesse deste trabalho. Entre os exemplos de intercâmbio através da modalidade de turismo colaborativo, podemos citar as plataformas WorkAway e Worldpackers, que tem como foco a troca de acomodação, em meios de hospedagem de diversas modalidades, por serviços prestados. Podemos citar ainda a plataforma World Wide Opportunities On Organic Farms (WWOOF), que realiza intermediações entre produtores proprietários de fazendas orgânicas e viajantes interessados na experiência de trabalhar nestes locais.

Foram analisados os seguintes objetivos específicos: investigar o interesse dos alunos da UFPel em relação à temática intercâmbio, detectar quais são as maiores dificuldades dos alunos da UFPel quando pensam em realizar intercâmbio, compreender o que os alunos da UFPel entendem do termo "turismo colaborativo", identificar qual a possibilidade dos alunos da UFPel se interessarem pela modalidade de intercâmbio via "work exchange" e avaliar o que os alunos da UFPel conhecem sobre as plataformas "work exchange".

\section{FUNDAMENTAÇÃO TEÓRICA}

Nesta seção, serão abordados quatro temas que se associam ao estudo: as plataformas "work exchange" como ferramenta para o Intercâmbio no turismo colaborativo: o que pensam os alunos da UFPel? Sendo assim, para 


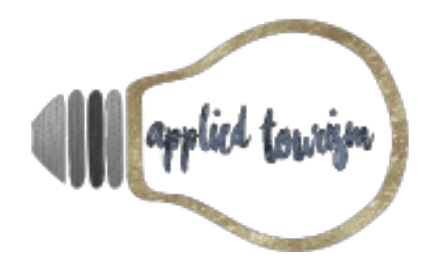

Volume 3, número 3, 2018, p. 13- 36

contemplar a temática estudada, problemas e objetivos que foram apresentados e cumprir a função de nortear a pesquisa, tornou-se importante apontar: conceitos de economia colaborativa, intercâmbio, turismo colaborativo e plataformas "work exchange". Dessa maneira, temos a intenção de indicar o embasamento da literatura publicada sobre tais definições, o que construirá a referência teórica para a análise do assunto estudado.

\section{ECONOMIA COLABORATIVA}

Hamari; Sjöklint e Ukkonen (2015) definem a economia colaborativa como um fenômeno emergente onde a economia e a tecnologia estão associadas ao constante crescimento das tecnologias de informação e comunicação, favorecendo seu desenvolvimento em conjunto com a conscientização dos indivíduos consumidores sobre o compartilhamento social.

Nessa mesma linha de pensamento a economia colaborativa atingiu os meios convencionais, promovendo uma discussão que contempla o espectro entre a economia convencional e a colaborativa, indicando que esta última é um fenômeno que merece atenção e análise para auxiliar no entendimento e escolha da modalidade mais adequada ao indivíduo consumidor (AVITAL et al, 2014).

Sundararajan (2013) indica que o consumo contínuo de tecnologias digitais está promovendo uma "reengenharia" fundamental na forma de consumir dos indivíduos, que permite uma escolha entre os modelos de acesso das plataformas peer-to-peer (plataformas ponto a ponto, P2P ${ }^{\mathrm{I}}$ ) baseados na produção colaborativa, onde o crescimento e a eficiência da produtividade podem ser elevados por inúmeras vias, tais como: diminuição dos custos de mercado, facilitação da produção, promoção de um nível maior de resultados a partir do mesmo padrão de ativos físicos e trabalho e a criação de oportunidades de produção e troca que não eram possíveis pela forma convencional.

O consumo colaborativo deixou de ser um nicho de trocas para tornar-se um fenômeno de larga escala, o qual envolve milhões de usuários e converteu-se em um investimento lucrativo, como um modelo competitivo que desafia os fornecedores de serviços convencionais (BOTSMAN; ROGER, 2011; LAMBERTON; ROSE, 2012).

O consumo colaborativo segundo Belk (2014) é descrito como pessoas coordenando a aquisição e distribuição de um recurso por uma taxa ou outra compensação, em sistemas ou redes organizadas, nas quais os participantes

\footnotetext{
I Plataforma Peer-to-peer (P2P) permitem a interação entre duas ou mais pessoas que comercializam ou trocam bens e serviços, mantidas por companhias, organizações ou plataformas que não estão diretamente envolvidas nas transações. (STOKES et al, 2014) Engelbrecht, R. F..; Yurgel, L. G. \& Pinheiro, P. M. S. (2018). O TURISMO COLABORATIVO COMO FERRAMENTA DE INTERCÂMBIO: Estudo de Caso em uma Universidade Brasileira. Applied Tourism, 3(3), 13- 36.
} 


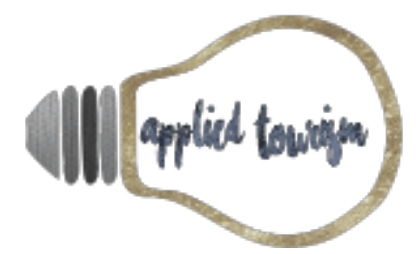

Volume 3, número 3, 2018, p. 13-36

conduzem as atividades de troca, nas formas de aluguel, crédito, comercialização e permuta de bens, serviços, transporte, espaço ou dinheiro, assim excluindo as atividades de troca onde não há compensação incluída.

A opção pelo modelo de consumo colaborativo apresenta dez variáveis determinantes que são: pertencer a uma comunidade, economia, impacto ambiental, familiaridade, potencial da rede internet, qualidade do serviço, potencial dos aplicativos dos smartphones, afinidade comercial, confiança e utilidade, sendo que apresenta em sua estrutura uma interdependência entre estas variáveis, apresentada na Figura 1 (MÖHLMANN, 2015).

Figura 1 - Estrutura das variáveis de escolha por uma opção de troca.

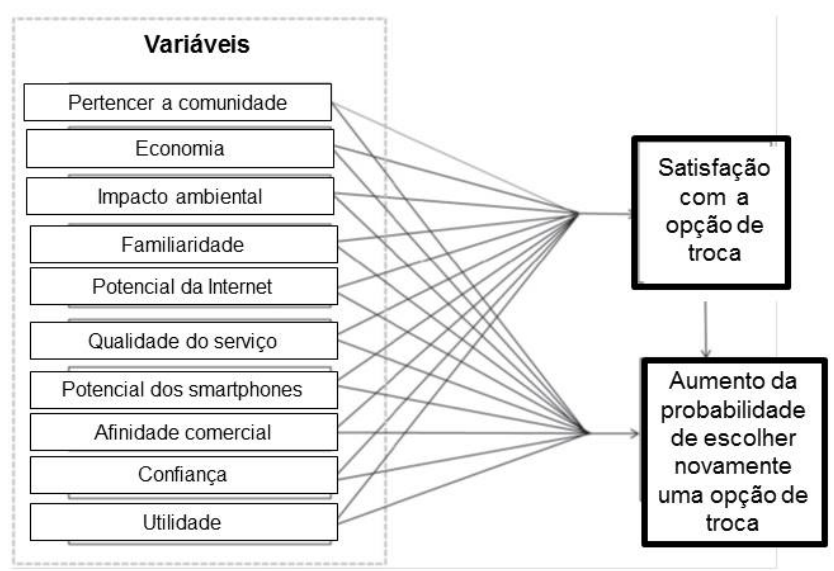

Fonte: Adaptado de MÖHLMANN, 2015.

A primeira variável, "Pertencer a comunidade", indica o surgimento do papel de uma coprodução colaborativa no comportamento de consumo, onde os membros de uma comunidade demonstram o desejo de fazer parte de um grupo através de práticas de troca de conhecimento ou bens por razões práticas ou ideológicas (BOTSMAN; ROGER, 2011).

Em sequência a variável "Economia" demonstra que a redução nos custos é um fator importante no consumo colaborativo, por permitir que os indivíduos envolvidos na modalidade de troca obtenham benefícios, já que usualmente as opções de troca apresentam custos mais baixos que as formas convencionais de negociação de produtos ou serviços (MOELLER \& WITTKOWSKI, 2010).

A variável "Impacto ambiental" representa o crescente movimento em direção ao modelo de consumo ético e sustentável, sendo uma das principais determinantes na opção por modalidades de troca, sendo as mesmas 


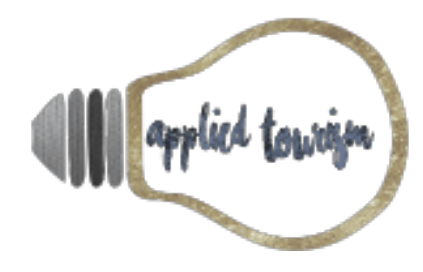

Volume 3, número 3, 2018, p. 13- 36

consideradas como tendo impacto positivo para o meio ambiente quando comparadas as modalidades convencionais de consumo, por reduzirem a produção de resíduos (HAMARI et al, 2015).

Em relação à "Familiaridade", é demonstrado que optar pela modalidade de troca depende do conhecimento que o consumidor possui acerca do assunto, portanto quanto mais familiarizado com os mecanismos envolvidos no processo de troca maior é a probabilidade de utilizar a troca como forma de realizar transações de bens e serviços (MOELLER; WIT'TKOWSKI, 2010).

O "Potencial da internet" revela que a tecnologia da internet propiciou uma redução dos custos nas transações comerciais e também uma redução dramática nas distâncias entre os consumidores, desta forma as opções de trocas foram facilitadas pelas plataformas presentes na internet, as quais permitem a comunicação entre as partes envolvidas promovendo as mais diversas modalidades de permuta (SLEE, 2013).

A sexta variável, "Qualidade do serviço" evidencia a satisfação do consumidor com a experiência de utilizar a modalidade de troca, formando uma opinião sobre a qualidade do serviço, já que obter uma avaliação positiva é o principal fator determinante para o uso continuado deste sistema (SEIDERS et al, 2007).

O "Potencial dos smartphones" representa o aumento da amplitude das formas de comunicação, o uso crescente dos telefones celulares, em especial os chamados smartphones, que possuem uma grande variedade de aplicativos, os quais asseguram um acesso imediato a inúmeros dados e serviços, permitindo que os usuários localizem produtos e serviços com facilidade, favorecendo a comunicação entre as comunidades de troca, intensificando assim seu uso (BOTSMAN; ROGERS, 2011).

Em seguida, "Afinidade comercial" esclarece a influência no comportamento do consumidor a respeito de uma determinada atividade comercial, sendo o consumo colaborativo um comércio emergente, a afinidade do consumidor pelo serviço ou produto oferecido é de vital importância para que o mesmo seja bem-sucedido (MOELLER; WITTKOWSKI, 2010).

A penúltima variável, "Confiança" evidencia a importância do comprometimento das partes envolvidas em uma modalidade de troca com as suas atribuições, no contexto do consumo colaborativo. Confiança refere-se tanto a prover um bem ou serviço, quanto ao compartilhamento destes com outros consumidores, desta forma a confiança é o cerne que leva os indivíduos à cooperação e a opção por uma modalidade de troca (BAUWENS, 2012). 


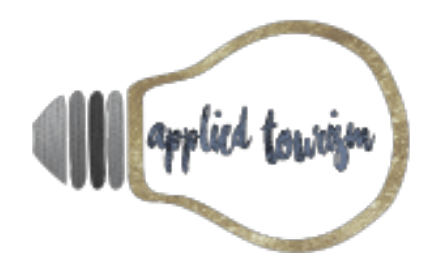

Volume 3, número 3, 2018, p. 13-36

Por fim, a "Utilidade" representa o desejo do consumidor em buscar um bem ou serviço que lhe proporcione a maximização da utilidade dos mesmos, a percepção do usuário sobre a utilidade de um determinado bem ou serviço faz com que haja uma comparação entre as modalidades de troca e as formas convencionais de oferta de produtos e serviços, influenciando assim a escolha final sobre forma mais adequada aquela necessidade particular (HENNING-THURAU et al, 2007).

A partir do exposto observamos que dentro da estrutura das variáveis, todas têm efeito na satisfação do usuário de modalidades de troca, compondo assim os elementos centrais que, quando apresentam efeitos positivos, influenciam a possibilidade de usar e repetir esta forma não convencional de comércio de bens e serviços (MÖHLMANN, 2015).

O processo de globalização, associado ao avanço das tecnologias de informação estimulam os indivíduos a realizar viagens com os mais diferentes objetivos, entre eles agregar cultura e conhecimento, aprendizado, praticar um idioma e ascensão no mercado de trabalho, podendo utilizar a modalidade de intercâmbio como ferramenta (TOMAZZINI; OLIVEIRA, 2013).

\section{INTERCÂMBIO}

O surgimento dos programas de intercâmbio apresenta divergências, segundo Shültz (2002 apud Arruda, 2004) os programas de intercâmbio direcionado a jovens tiveram origem nos Estados Unidos depois da Segunda Guerra Mundial tendo por objetivo promover o entendimento entre as nações e o respeito às diferenças culturas, já Giaretta (2003) indica o turismo como base da modalidade de intercâmbio educacional, com surgimento na Inglaterra no século XVII. Mesmo sem apresentar um consenso a respeito da origem do intercâmbio, observa-se que o objetivo de fomentar o aumento do conhecimento sobre as diferentes culturas é o mote fundamental dos programas de intercâmbio, independentemente de sua origem.

O Intercâmbio apresenta diversas modalidades, Giaretta (2003) cita como exemplos viagens para cursos de idiomas no exterior, viagens de intercâmbio turístico, viagens com bolsas de estudos para universidades no exterior, cursos de especialização, visitas técnicas realizadas em instituições de ensino, viagens de formatura, viagens de estudo do meio, estágios no exterior, Au Pair ${ }^{I I}$, Work Experience, entre outras.

\footnotetext{
${ }^{\text {II }}$ É um programa com duração de três meses a um ano (dependendo do destino), onde o participante mora em uma casa de família com as despesas de acomodação e alimentação pagas e é remunerado pelo cuidado com as crianças.

Engelbrecht, R. F..; Yurgel, L. G. \& Pinheiro, P. M. S. (2018). O TURISMO COLABORATIVO COMO FERRAMENTA DE INTERCÂMBIO: Estudo de Caso em uma Universidade Brasileira. Applied Tourism, 3(3), 13- 36.
} 


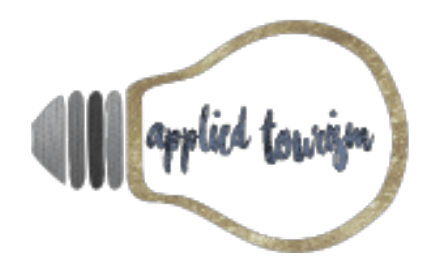

Volume 3, número 3, 2018, p. 13- 36

Uma das modalidades de intercâmbio é o chamado intercâmbio educacional onde o estudante pode realizar parte dos seus estudos, tanto na graduação quanto na pós-graduação, em uma instituição de ensino sediada no exterior, possibilitando assim uma complementação e ampliação na formação profissional, baseada na troca de conhecimentos, experiências e vivência de uma nova cultura (VIEIRA et al, 2011).

O intercambista está diretamente envolvido nas mais diversas dimensões da vida cotidiana do ambiente onde está inserido, o que promove uma maior compreensão das particularidades acerca das diferenças culturais, segundo Arruda (2004):

Conviver como membro de uma sociedade diferente da de origem causa a sensação nos jovens e nos pais que incentivam seus filhos a participarem do programa de intercâmbio, a sensação de que estão aptos a lidar, em seu futuro profissional, com pessoas de diferentes culturas com maior facilidade (ARRUDA, 2004, p. 209).

No âmbito profissional, realizar um programa de intercâmbio é considerado um diferencial na qualificação, não apenas pela fluência em um idioma estrangeiro, mas principalmente pelo amadurecimento proporcionado pela experiência ao intercambista, indicando que pessoas que vivenciam um intercâmbio tornam-se mais maduras, independentes e flexíveis (BORGES, 2008).

Além do aspecto profissional, os indivíduos realizam viagens com o objetivo de lazer, conhecer outra cultura ou um local, o que caracteriza as viagens turísticas, dentro deste universo surgiu o turismo colaborativo.

\section{TURISMO COLABORATIVO}

O turismo representa uma importante atividade que promove desenvolvimento socioeconômico do local visitado, entretanto nem sempre produz uma influência positiva em outros aspectos da localidade, desta forma novas concepções a respeito desta atividade que levam em consideração as dimensões sociais, culturais e ambientais tem emergido, orientando novas formas de gestão e consumo da experiência turística, o turismo é apontado como o setor econômico que mais cresce mundialmente (CARNEIRO et al, 2010; UNWTO, 2015).

Segundo Uribe-Echevarria (2017) o turismo é uma atividade dinâmica, que sofre alterações com o tempo, resultando em novas modalidades e tendências, as tecnologias de informação e a comunicação atuam como agentes modificadores da atividade turística, promovendo assim a expansão e a diversificação do turismo, influenciada pelos usuários que atualmente buscam viagens que fogem dos padrões tradicionais. 


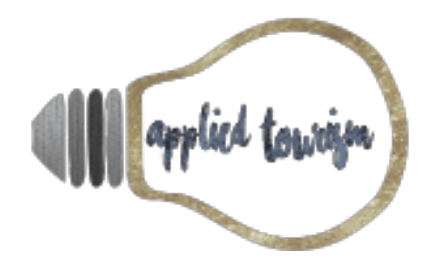

Volume 3, número 3, 2018, p. 13- 36

Dentre as inovações surge o turismo colaborativo, que apesar de configurar um conceito relativamente novo, apresenta uma demanda de crescimento constante, as características peculiares do turismo colaborativo o torna muito diferente do turismo tradicional, onde a figura do agente de viagem não é mais necessária e surgem novos produtos e serviços que substituem os tradicionalmente oferecidos, as negociações são realizadas de forma direta ou utilizando as plataformas P2P como intermediárias (URIBE-ECHEVARRIA, 2017).

Os avanços sociais e econômicos ao longo do tempo incentivam e incrementam as disponibilidades de renda e tempo livre. Mais recentemente, com a incorporação de novas tecnologias, principalmente nas áreas de transportes e telecomunicações, consolida-se uma nova era de viagens e lazer (FERNANDES; COELHO, 2002, p. 121)

No século XXI observa-se que viajar constitui-se em hábito para os indivíduos, por várias razões, tais como, status social, negócios, estudos ou lazer, o turismo contemporâneo caracteriza o ser humano como um ser tão globalizado quanto a sociedade em que vive (TRIGO, 2003).

A evolução tecnológica produziu ferramentas específicas para aproximar os viajantes e os fornecedores de bens e serviços, com isso observamos o desenvolvimento das plataformas que possibilitam a troca entre os indivíduos, nascendo assim as plataformas work exchange.

\section{PLATAFORMAS WORK EXCHANGE}

A tecnologia das plataformas P2P possibilitaram inicialmente o compartilhamento de arquivos e o comércio de bens físicos, com o desenvolvimento constante das formas de comunicação houve uma evolução da tecnologia P2P o que permitiu, além do seu uso inicial, o surgimento de plataformas que facilitaram a troca de serviços ou financiamentos, emergindo assim um sistema operacional social independente da hierarquia tradicional, onde observou-se uma relação coletiva mais fluída entre os usuários (GANSKY, 2010).

Botsman e Rogers (2011) desenvolveram a ideia central apresentada por Gansky (2010), onde descreveram a ruptura do modelo econômico convencional, originando a economia colaborativa ou de compartilhamento, a qual criou um mercado eficiente que comporta novos produtos, reestruturou os serviços estabelecidos e gerou um crescimento econômico global.

Na última década a economia baseada na troca de bens e serviços entre indivíduos cresceu consideravelmente, principalmente devido à proliferação das plataformas P2P na rede mundial de computadores, as quais 


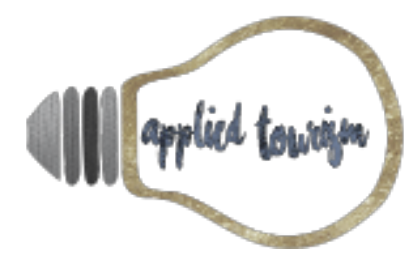

Volume 3, número 3, 2018, p. 13-36

compartilham recursos e permitem trocas efetivas a um custo relativamente baixo, quando comparado às formas tradicionais de comércio de bens e serviços (AVITAL, 2014).

A economia colaborativa apresenta cinco características básicas: uso facilitado pelas tecnologias da internet; conexão das redes de pessoas e/ou bens; utilização da capacidade ociosa de bens tangíveis ou intangíveis; estimulo de interações significativas de confiança e abranger disponibilidade; e inclusão e compartilhamento (STOKES et al, 2014).

Os modelos de negócios utilizados na economia colaborativa incluem as plataformas, Business-to-Consumer (B2C) representando a interação entre consumidores e companhias que gerenciam diretamente seus produtos, Business-to-Business (B2B) onde ocorre a interação entre empresas: Peer-to-Peer (P2P) a interação se dá entre duas ou mais pessoas que comercializam ou trocam bens e serviços, mantidas por companhias, organizações ou plataformas que não estão diretamente envolvidas nas transações; e o modelo Consumer-to-Business (C2B) quando o consumidor interage com uma empresa onde há o pagamento de bens ou serviços adquiridos pelo indivíduo diretamente à companhia envolvida na transação comercial (STOKES et al, 2014).

A economia colaborativa representa o principal fator de crescimento econômico e inovação social, estima-se que na Europa o modelo colaborativo P2P para acomodação é o setor de maior crescimento tendo movimentado em torno de 15,1 milhões de Euros em 2015 (PWC, 2015)

O modelo de economia P2P utiliza a tecnologia digital para conectar o anfitrião (produtor) aos hóspedes (consumidores), possibilitando que qualquer indivíduo que possua uma acomodação a disponibilize no mercado global para utilização, gerando assim uma grande diversidade de produtos de hospedagem, com uma consequente diminuição nos custos para o consumidor, sendo este um dos principais fatores que levam ao crescimento significativo da economia P2P para acomodação (conforme colocado no site da Comissão Europeia, 2016).

As plataformas de economia P2P para acomodação facilitam as transações no espaço digital, onde o consumidor paga uma taxa e recebe informações sobre a hospedagem desejada, fornecendo um conjunto de ações que incluem, serviços de transação e administração, verificação dos procedimentos para os usuários, propaganda e avaliação da plataforma (DREDGE et al, 2016).

Os usuários possuem percepções diferentes sobre o serviço que lhe foi ofertado, desta forma as plataformas devem conhecer as atitudes e preferências básicas do cliente, focando principalmente nas suas necessidades e 


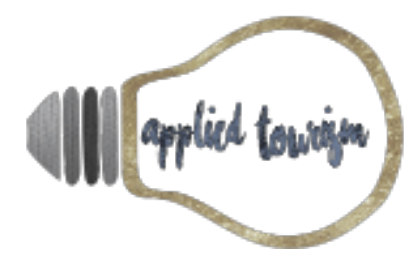

Volume 3, número 3, 2018, p. 13-36

expectativas, visto que a qualidade do serviço oferecido é fundamental para o usuário e está associado diretamente ao comprometimento de quem vai prestá-lo (BANDEIRA et al, 2007).

Um estudo realizado por Tiellet (2008) identificou que a modalidade de intercâmbio com o crescimento mais significativo no Brasil é a que propõe a troca da força de trabalho pelo turismo, o que resulta em um programa de menor custo, facilitando a vivência desta experiência por usuários com menor poder aquisitivo, os quais teriam dificuldade em realizá-la pelos mecanismos convencionais.

\section{METODOLOGIA}

O estudo pode ser considerado, do ponto de vista de seus objetivos, exploratório e descritivo. A pesquisa exploratória é particularmente útil quando o responsável pelas decisões dispõe de poucas informações (HAIR et al, 2005). Para Malhotra (2001, p. 106), seria "um tipo de pesquisa que tem como principal objetivo o fornecimento de critérios sobre a situação-problema enfrentada pelo pesquisador e sua compreensão". É caracterizada por flexibilidade e versatilidade com respeito aos métodos, porque não são empregados protocolos e procedimentos formais. Esta pesquisa pode ser considerada exploratória pois poucos são os estudos realizados sobre o turismo colaborativo como ferramenta de intercâmbio.

Segundo Vergara (2000) a pesquisa descritiva expõe as características de determinada população ou fenômeno, estabelece relações entre variáveis e define sua natureza. Para Cooper e Schindler (2003), entre os objetivos da pesquisa descritiva está a descrição de fenômenos ou características associadas com a população-alvo (o que, quem, quando, onde e como de um tópico). Esta pesquisa pode ser assim considerada pois descreverá o panorama do turismo colaborativo como ferramenta de intercâmbio na Universidade Federal de Pelotas (UFPel).

Como procedimento técnico, visando a obtenção dos resultados, será realizado um estudo de caso a partir de um questionário aplicado aos alunos da UFPel. Estudo de caso, segundo Yin (2001, p. 32 ) é "um fenômeno dentro do seu contexto da vida real". Para Triviños (1987, p. 133-4), "o estudo de caso é um estudo profundo que possibilita conhecimento amplo e detalhado de um objeto de pesquisa. O objetivo consiste em estudar profundamente e analisar de forma intensa os fenômenos que constituem o ciclo vital da unidade".

Da forma como é abordada, esta pesquisa pode ser considerada quantitativa e qualitativa. Na abordagem qualitativa, o objeto é o fator determinante para a escolha de um método, os objetos são estudados em sua complexidade e totalidade (FLICK, 2004). Já a pesquisa quantitativa procura quantificar os dados, traduzir as opiniões e informações em números e aplicar alguma forma de análise estatística (MALHOTRA, 2001). 


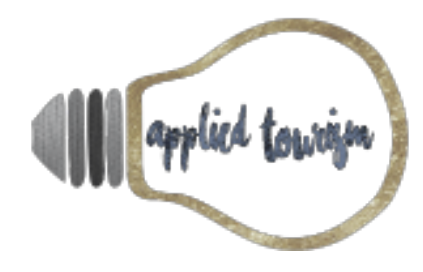

Volume 3, número 3, 2018, p. 13- 36

O grupo de sujeitos deste estudo foram discentes da UFPel, dos diversos cursos da Instituição, abrangendo os níveis de graduação e pós-graduação. A UFPel é uma instituição de ensino superior (IES) sediada na cidade de Pelotas, Rio Grande do Sul. A IES possui mais de 100 cursos de graduação, bem como, diversos programas de pós-graduação vinculados a diversas áreas do conhecimento. A universidade possui cerca de 14 mil alunos matriculados, segundo o último Censo da Educação Superior (2014) ${ }^{\text {III. }}$.

O questionário (Figura 2) foi composto por 15 perguntas, abertas e fechadas, produzido através de uma ferramenta da plataforma Google chamada Google Forms, utilizada para criar formulários e facilitar a divulgação online, assim como o recebimento das respostas.

O questionário ficou disponível no grupo UFPel da rede social Facebook do dia 12/07/2017 até o dia 17/07/2017, totalizando 121 respondentes, sendo que desses 8 foram excluídos por não constarem informações corretas. Nesses casos, verificou-se inconsistências em relação a nome do curso (não existente na UFPEL) e erro de preenchimento dos campos solicitados, sendo aproveitados 113 questionários.

Figura 2 - Perguntas do questionário.

\begin{tabular}{|l|l|l|}
\hline 1 - Qual a sua idade? & $\begin{array}{l}\text { 6 - Se não, você gostaria de fazer um } \\
\text { intercâmbio? }\end{array}$ & $\begin{array}{l}\text { 11-Se sim, o que você compreende por turismo } \\
\text { colaborativo. }\end{array}$ \\
\hline 2-Gênero & 7 - Qual seria a sua motivação? & $\begin{array}{l}12 \text { - Você faria um intercâmbio via "work } \\
\text { exchange" }\end{array}$ \\
\hline 3-Curso & 8 - Qual destino seria do seu interesse? & $\begin{array}{l}13 \text { - Em que área você teria interesse em } \\
\text { trabalhar? }\end{array}$ \\
\hline 4- Você já fez um intercâmbio? & $\begin{array}{l}\text { 9 - Quais as maiores dificuldades para realizar } \\
\text { um intercâmbio? }\end{array}$ & $\begin{array}{l}14 \text { - Você conhece alguma plataforma de "work } \\
\text { Exchange"? }\end{array}$ \\
\hline 5- Se sim, faria novamente? & 10 - Você conhece o turismo colaborativo? & 15- Se sim, qual? \\
\hline
\end{tabular}

Fonte: elaborado pelos autores.

Os dados receberam um tratamento quali-quantitativo, onde foi realizada uma categorização dos dados. Segundo Bardin (2011), a análise categorial destaca-se entre as técnicas utilizadas para análise de conteúdo, uma vez que trata do desmembramento das informações em categorias, onde os critérios de escolha e de delimitação orientam-se pela dimensão da investigação dos temas relacionados ao objeto de pesquisa, identificados nas informações dos sujeitos pesquisados.

\footnotetext{
III Informações retiradas do site da instituição: www.ufpel.edu.br e do Ranking de Universidades da Folha 2016, disponível em: http://ruf.folha.uol.com.br/2016/perfil/universidade-federal-de-pelotas-ufpel-634.shtml 


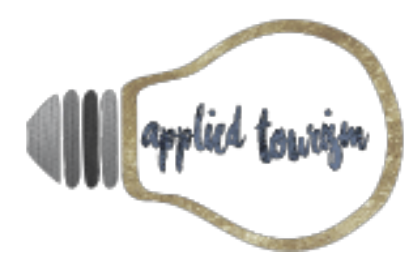

Volume 3, número 3, 2018, p. 13- 36

A categorização dos dados para o estudo está representada na Figura 3, onde as questões 1, 3 e 8 por se tratarem de questões abertas apresentaram uma variedade de respostas, por esta razão foram agrupadas em áreas de maior abrangência, sendo estas, faixas etárias de acordo com a menor e a maior idade obtida, nas grandes áreas do conhecimento dos cursos da IES e em regiões geográficas.

Nas demais questões apresentadas na Figura 3, os respondentes optavam por uma resposta pré-estabelecida. As questões 11 e 15 por sua característica descritiva não foram analisadas estatisticamente, por esse motivo não constam na figura 3.

Figura 3 - Esquema de categorização dos dados.

\begin{tabular}{|l|l|l|}
\hline Questão 1 (Idade) & Questão 4 (Intercâmbio) & Oriente Médio \\
\hline $18-20$ & Sim & América Central \\
\hline $21-30$ & Não & América do Sul \\
\hline $31-40$ & Questão 5* & Ásia \\
\hline $41-50$ & Sim & Outros \\
\hline $51-60$ & Não & Questão 9 (Dificuldade) \\
\hline Questão 2 (Sexo) & Talvez & Financeiras \\
\hline Feminino & Questão 6* & Disponibilidade de tempo \\
\hline Masculino & Sim & Falta de informações \\
\hline Questão 3 (Curso) & Não & Outros \\
\hline Ciências Exatas e da Terra & Talvez & Questão 10 (Turismo Colaborativo) \\
\hline Ciências Biológicas & Questão 7 (Motivação) & Sim \\
\hline Engenharias & Conhecer nova cultura & Não \\
\hline Ciências da Saúde & Estudos & Questão 12 (Intenção) \\
\hline Ciências Agrárias & Trabalho & Sim \\
\hline Ciências Sociais e Aplicadas & Turismo & Não \\
\hline Ciências Humanas & Outros & Questão 13 (Área) \\
\hline Linguística, Letras e Artes & Questão 8 (Destino) & Somente na sua área de formação \\
\hline Outros & Oceania & Qualquer área \\
\hline Pós-Graduação & Europa & Questão 14 (Plataforma) \\
\hline & África & Sim \\
\hline & América do Norte & Não \\
\hline
\end{tabular}

Fonte: elaborado pelos autores.

\section{RESULTADOS E DISCUSSÕES}

Com a finalidade de responder os objetivos dessa pesquisa, os dados foram analisados de acordo com a sua frequência e porcentagem. Esses resultados serão apresentados em forma de gráficos, que facilitam a interpretação e compreensão. 


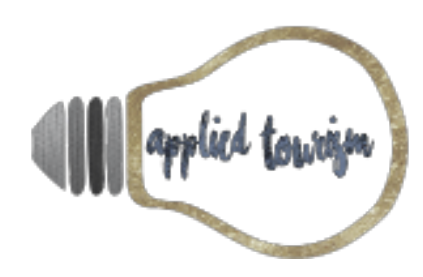

Volume 3, número 3, 2018, p. 13-36

Figura 4-Gráfico exibindo a faixa etária dos participantes.

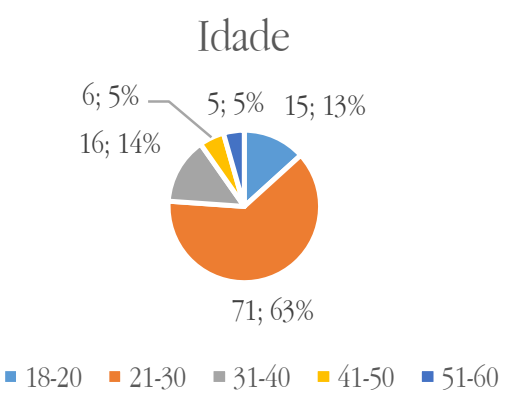

Fonte: elaborado pelos autores.

Dos 113 questionários analisados, nota-se o predomínio da faixa etária de 21 a 30, com 71 respostas (63\%, $\mathrm{n}=113$ ), o que era esperado por se tratar da idade mais usual dos acadêmicos de uma instituição de ensino superior. Porém importante salientar a presença de 11 respondentes $(10 \%, \mathrm{n}=113)$ acima dos 40 anos.

A segunda questão (figura 5) indagava sobre o sexo dos participantes, afim de posteriormente criar um perfil relacionado com outras respostas obtidas. Os dados indicaram que o sexo feminino teve predominância com 85 (75\%) de questionários respondidos e 28 (25\%) respondidos pelo sexo masculino.

Figura 5 - Gráfico exibindo o sexo dos participantes.

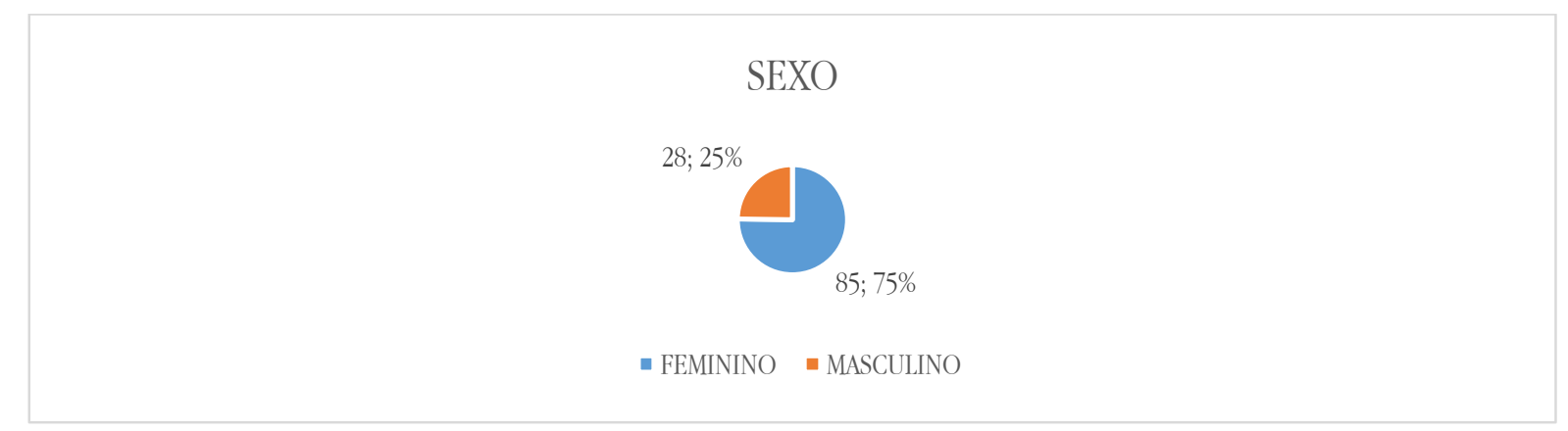

Fonte: elaborado pelos autores.

A figura 6 é referente a questão 3 que indagava sobre o curso que o respondente frequenta na UFPel, para facilitar a compreensão as respostas foram agrupadas nas grandes áreas do conhecimento, de acordo com o a Tabela de Áreas do Conhecimento do CNPq. 


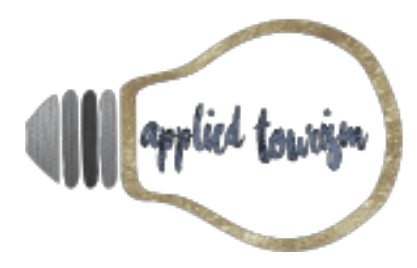

Volume 3, número 3, 2018, p. 13-36

Entre as grandes áreas, apenas a área das Engenharias não aparece nas respostas. Com o maior número de respondentes temos a área das Ciências Sociais Aplicadas com 34 respostas (30\%) seguido das Ciências da Saúde com 20 respostas (18\%). Os cursos de Pós-Graduação foram responsáveis por 5\% do resultado com 6 respostas.

Figura 6 - Gráfico exibindo as áreas de conhecimento utilizadas.

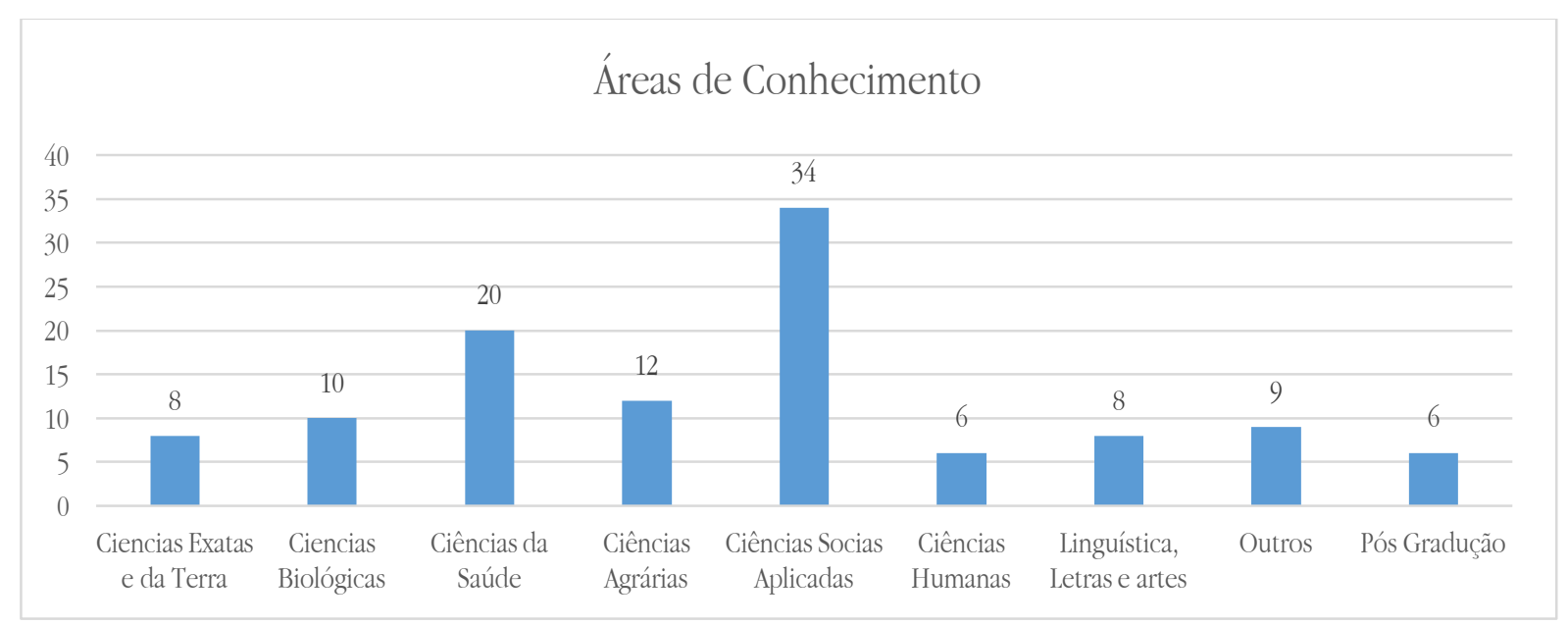

Fonte: elaborado pelos autores.

Quando perguntado se o aluno já havia realizado intercambio, descobriu-se que de um total de 113 respondentes, 99 (88\%) não realizaram, como mostra a Figura 7.

Figura 7 - Gráfico exibindo as respostas de realização, ou não, de intercâmbio.

Realização de Intercâmbio

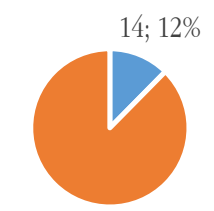

$99 ; 88 \%$

- SIM — NÃO

Fonte: elaborado pelos autores. 


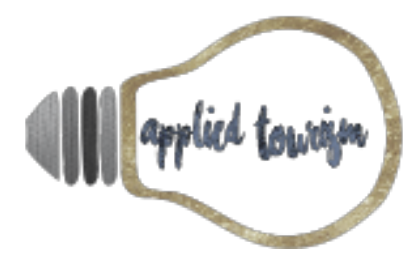

Volume 3, número 3, 2018, p. 13- 36

As perguntas 5 e 6 são relacionadas as respostas da pergunta 4 , a pergunta 5 referia-se à possibilidade de repetir a experiência para aqueles respondentes que já haviam realizado intercâmbio, já a pergunta 6 era direcionada aos sujeitos que não realizaram intercâmbio, onde constatou-se que em ambos os casos a maioria demonstra interesse em vivenciar a experiência de intercâmbio, seja pela primeira vez ou novamente.

Com base nesse interesse, foi questionado qual seria a motivação dos alunos em fazer um intercâmbio, quatro variáveis surgiram, a partir das respostas obtidas no questionário. No Figura 8 é possível analisar as áreas motivadoras.

Figura 8 - Gráfico exibindo as áreas de motivação.

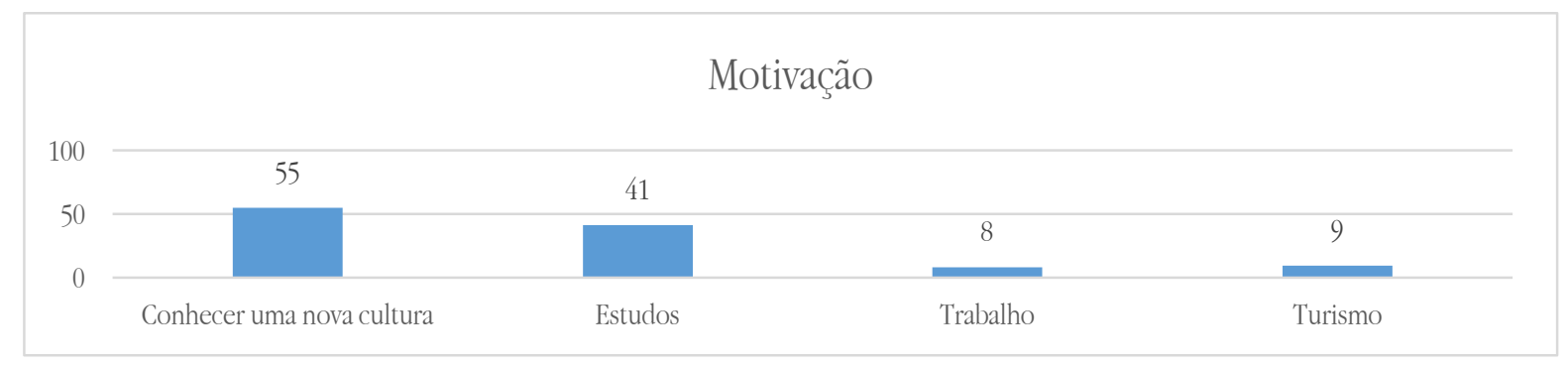

Fonte: elaborado pelos autores.

A principal motivação, com 55 respostas (49\%) é a vontade de conhecer uma nova cultura que se assemelha com proposto por Barreto (2003) que indicam que o intercâmbio tem como objetivo fomentar o aumento do conhecimento sobre as diferentes culturas.

A motivação visando estudos também apareceu em grande número totalizando 41 respostas (36\%), o que era esperado tratando-se de estudantes. O intercâmbio estudantil é uma das modalidades mais comuns de intercâmbio que acordo com Vieira (2011) é onde o estudante pode realizar parte dos seus estudos, possibilitando uma complementação e ampliação na formação profissional.

Acerca dos destinos de interesse dos alunos, as respostas apareceram com diversas opções, sendo assim para facilitar a compreensão, os locais foram agregados de acordo com seu continente ou região (Figura 9). O principal destino de interesse dos alunos é a Europa que aparece em 58 respostas sendo responsável por 51\% do total, alguns dos países mais citados foram Portugal, Espanha, Itália e Alemanha, seguido pela América do Norte com 21 respostas (19\%). 


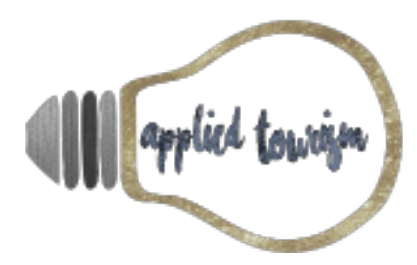

Volume 3, número 3, 2018, p. 13-36

Figura 9 - Gráfico exibindo os destinos de interesse.

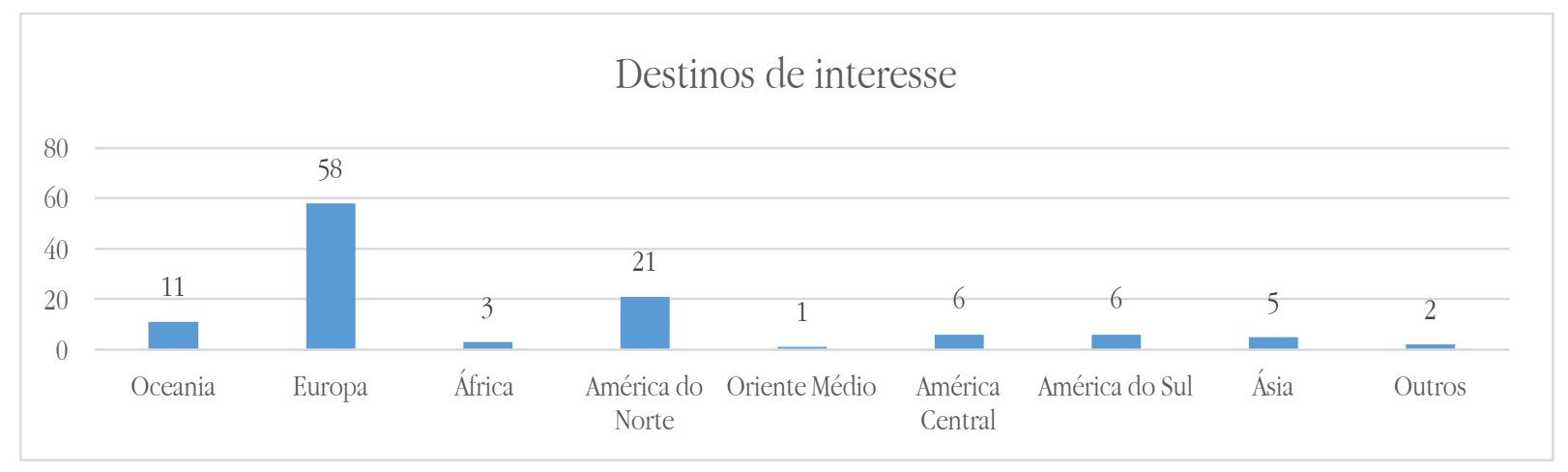

Fonte: elaborado pelos autores.

Como exceção, foram obtidas duas respostas incomuns uma delas fazia referência a locais que predominassem religiões de bem e paz de espirito e outra resposta foi 'qualquer', as duas foram encaixadas na categoria outros da figura 9.

De acordo com os objetivos da pesquisa, que eram de analisar quais os anseios dos alunos em relação ao intercâmbio, na questão 9 foi perguntado o que eles consideravam como dificuldade para realizar um intercâmbio. A Figura 10 representa esses dados.

A maior dificuldade percebida foi a financeira, o que é natural vindo de estudantes onde a maioria ainda não ingressou no mercado de trabalho. Outro fato também é a ligação automática que se faz do intercâmbio ao exterior, o que inclui gastos maiores.

Figura 10 - Gráfico exibindo as dificuldades apontadas pelos respondentes.

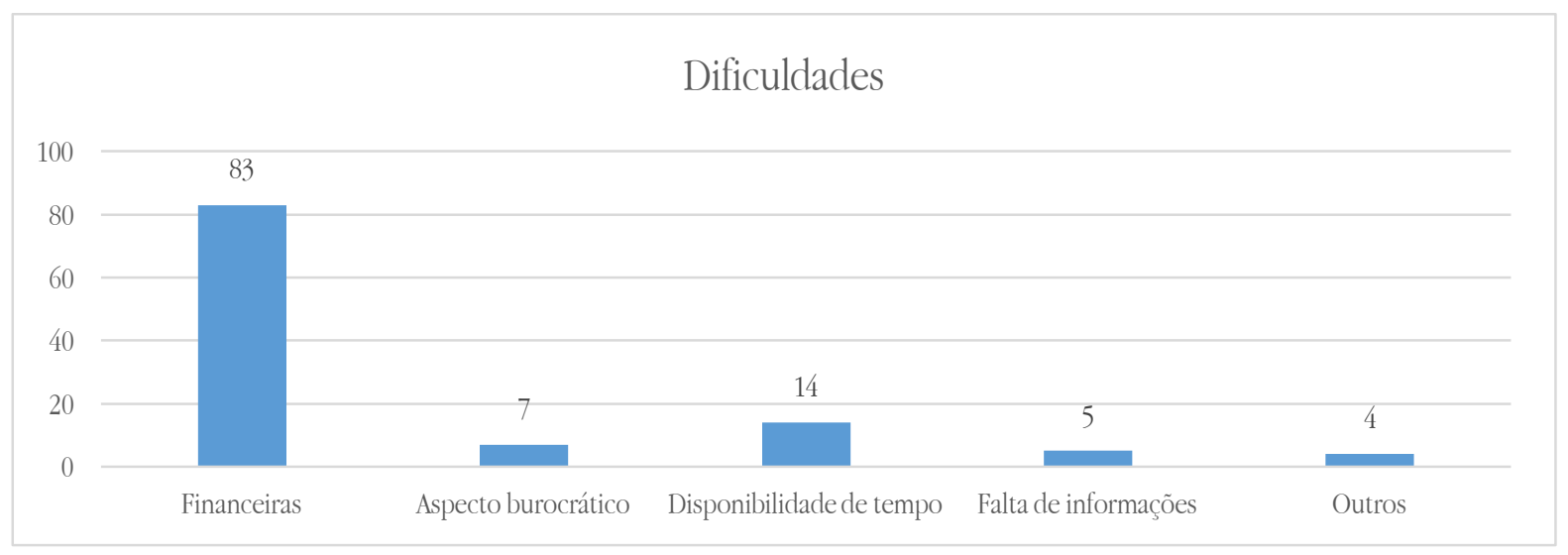

Fonte: elaborado pelos autores. 


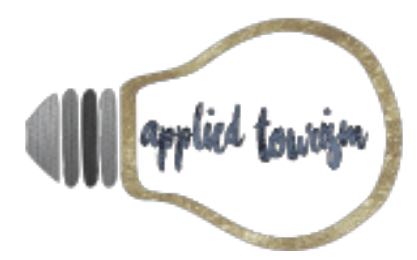

Volume 3, número 3, 2018, p. 13-36

A questão 10 tratou de abordar sobre o conhecimento de um novo conceito o chamado Turismo Colaborativo. A Figura 11 representa que 90\% dos respondentes não conhecem o Turismo Colaborativo, isso corrobora com a informação que o esse conceito é relativamente novo.

Figura 11 - Gráfico exibindo as respostas frente ao tema do turismo colaborativo.

\section{Turismo Colaborativo}

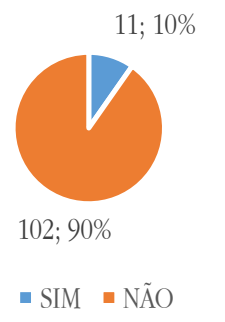

Fonte: elaborado pelos autores.

Os 11 participantes que responderam que conheciam, na pergunta seguinte foram instigados a dizer o que compreendiam do conceito, e dentro das respostas encontramos troca de experiências, sistema de permutas, alternativa para reduzir os custo de viagens, algo ligado a economia compartilhada, troca de benefícios, troca de trabalho por acomodação, divisão de espaços o que vem a concordar com Belk (2014) que descreve a economia colaborativa como sistemas ou redes organizadas, nas quais participantes conduzem atividades de troca, formas de aluguel, crédito, comercialização e permuta de bens, serviços, transportes, espaço ou dinheiro, excluindo atividades de troca onde não há compensação incluída.

$\mathrm{Na}$ questão seguinte, foi perguntado se o participante faria um intercâmbio via "work exchange" (troca de trabalho por acomodação), que complementa a questão anterior, por esta ser uma forma de intercâmbio que faz parte do sistema de economia colaborativa.

Figura 12 - Gráfico exibindo as respostas quanto ao interesse de intercâmbio via "work exchange".

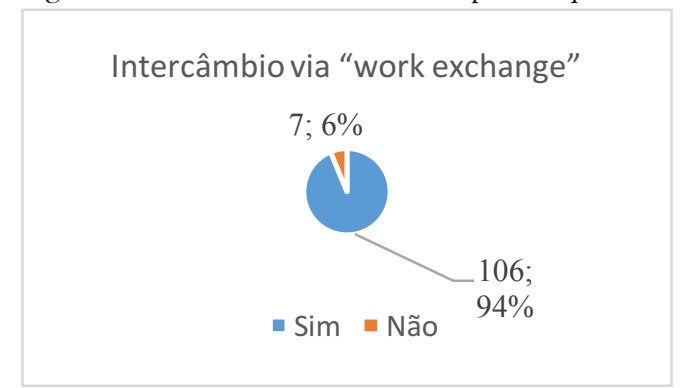

Fonte: elaborado pelos autores. 


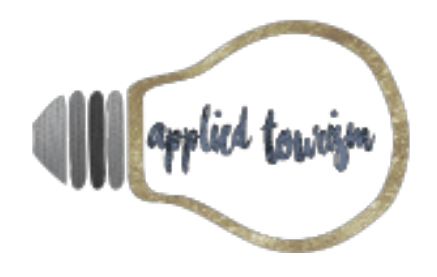

Volume 3, número 3, 2018, p. 13- 36

Apesar da falta de informações sobre turismo colaborativo, 94\% dos respondentes fariam um intercâmbio via troca de trabalho por acomodação (Figura 12). A questão 13 teve por objetivo descobrir se os alunos fariam um intercâmbio via "work exchange" somente se estivesse relacionado a sua área de formação ou se trabalhariam em qualquer área desde que se considerassem aptos para a tarefa.

A Figura 13 demonstra que a maior parte dos respondentes estariam dispostos a trabalhar em qualquer, desde que se considerassem aptos ou habilidosos.

Figura 13 - Gráfico exibindo as respostas quanto a possiblidade de trabalhar, ou não, em área distinta da sua formação.

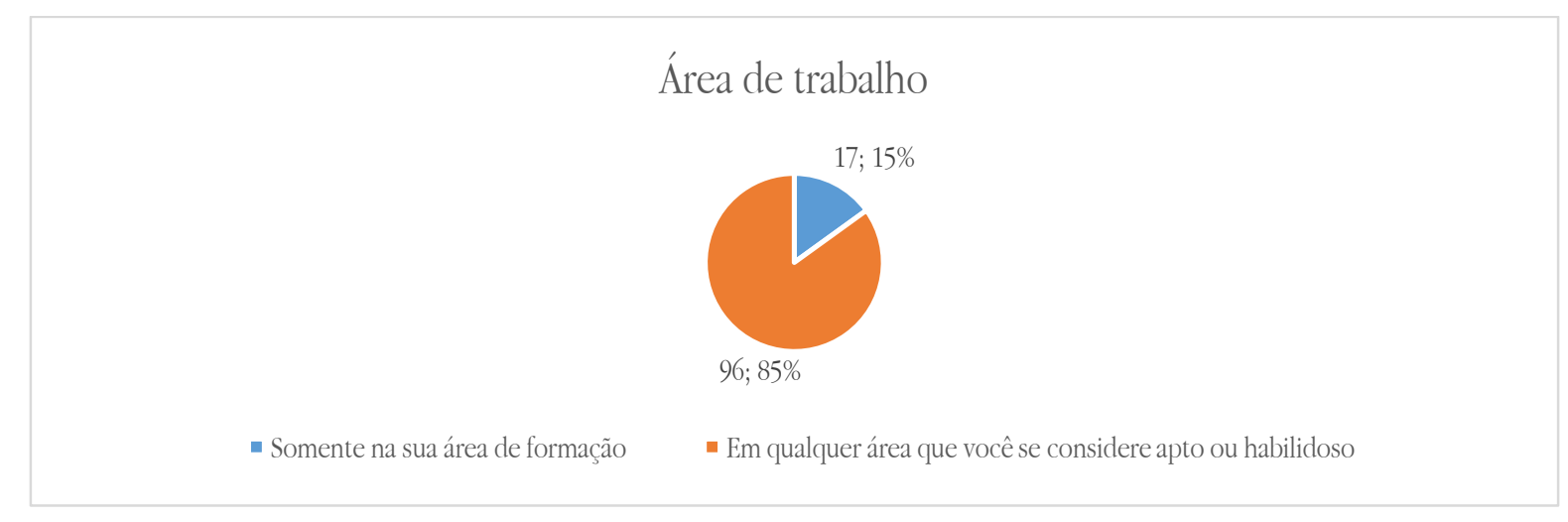

Fonte: elaborado pelos autores.

Isso nos remete à Arruda (2004) que diz que o intercambista está diretamente envolvido nas mais diversas dimensões da vida cotidiana do ambiente o que está inserido, o que promove mais compreensão das diferenças culturais. Com essa afirmação, é possível perceber que o intercambista deve estar disposto a vivenciar diferentes hábitos, culturas.

As duas últimas questões referem-se diretamente às plataformas de "work exchange", onde os respondentes foram questionados sobre o conhecimento acerca delas e em caso afirmativo fornecer exemplo (Figura 14). Como era esperado, de acordo com respostas anteriores, $90 \%$ dos estudantes não conhece nenhuma plataforma que promova o "work exchange", porém obtivemos 11 respostas positivas e foram citados como exemplos Worldpackers, Workaway, Wwoof Couchsurfing, AISEC, Hostels. Com exceção dos hostels, que não são plataformas e sim um tipo de estabelecimento de hospedagem, os outros podem ser considerados plataformas que promovem o "work exchange" em diferentes maneiras. 


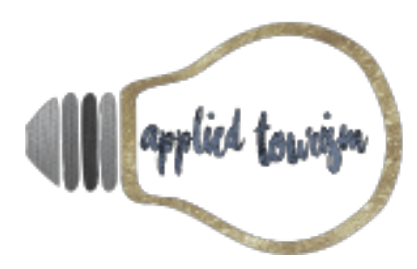

Volume 3, número 3, 2018, p. 13- 36

Figura 14 - Gráfico exibindo as respostas quanto ao conhecimento das plataformas de "work exchange".

Conhecimento sobre plataformas "work exchange"

$11 ; 10 \%$

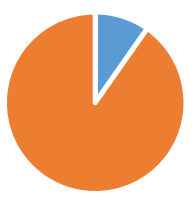

$102 ; 90 \%$

- Sim I Não

Fonte: elaborado pelos autores.

A segunda categoria de analise utilizada é a correlação que busca perceber se existem ligações entre as variáveis pesquisadas. Conforme apresentadas na figura 15. Foram encontradas 7 correlações significativas entre as variáveis, sendo 4 delas positivas e 3 negativas.

Figura 15 - Quadro de Correlações de Pearson.

\begin{tabular}{|c|c|c|c|c|c|c|c|c|c|c|c|}
\hline & Idade & Sexo & Curso & Interc & Motiv & Desti & Dificul & Tur. Col & Inten & Área & Plat \\
\hline Idade & 1 & & & & & & & & & & \\
\hline Sexo &,- 021 & 1 & & & & & & & & & \\
\hline Curso &, $187^{*}$ &, 031 & 1 & & & & & & & & \\
\hline Intercâmbio &, 073 &,- 033 &,- 015 & 1 & & & & & & & \\
\hline Motivação &,- 150 &,- 064 &, 045 &, 102 & 1 & & & & & & \\
\hline Destino &,- 026 &, 096 &, 030 &,- 030 &,- 156 & 1 & & & & & \\
\hline Dificuldade &, $203^{*}$ &,- 044 &, 146 &, 128 &, 054 &, 084 & 1 & & & & \\
\hline Tur. Col. &,- 174 &,- 157 &,$- 186^{*}$ &,- 033 &, 105 &,- 115 &,- 153 & 1 & & & \\
\hline Intenção &,- 111 &,- 062 &,- 145 &, 097 &, $236^{*}$ &, 083 &, 098 &, 084 & 1 & & \\
\hline Área &, 055 &, 116 &, 071 &,- 076 &,$- 229^{*}$ &,- 136 &,- 085 &,- 133 &,$- 317^{* *}$ & & 1 \\
\hline Plataforma &,- 042 &,- 088 &,- 097 &,- 033 &,- 027 &,- 100 &,- 126 &, $295^{* *}$ &, 084 &,- 133 & 1 \\
\hline
\end{tabular}

Fonte: elaborado pelos autores.

*. A correlação é significativa no nível 0,05 (2 extremidades). **. A correlação é significativa no nível 0,01 (2 extremidades). 


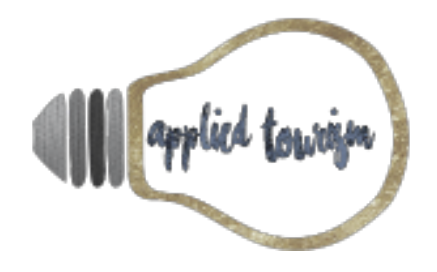

Volume 3, número 3, 2018, p. 13- 36

As positivas são entre as variáveis idade e curso (,187), idade e dificuldade (,203), motivação e intenção (,236) e plataforma e turismo colaborativo (,295). E as negativas são entre curso e turismo colaborativo (-,186), motivação e área $(-, 229)$ e intenção e área (-,317), resultados grifados no Figura 15.

A correlação entre idade e curso por mais que seja significativa, é bastante baixa, isto pode ser explicado pela amplitude dos dados, onde percebe-se uma predominância das faixas etárias de 21-30 e 31-40 em todas as áreas. E uma presença de respondentes de mais de 50 anos nas Ciências Sociais Aplicadas e em Outros.

Seguindo com a correlação positiva entre idade e dificuldade nota-se a disponibilidade de tempo e falta de informação tendem a aparecer mais nas faixas etárias acima dos 40 anos, enquanto aspectos financeiros e burocráticas estão mais presentes nas faixas etárias inferiores.

As motivações em conhecer novas culturas e viajar a estudos, estão fortemente ligadas a intenção de realizar um intercâmbio como mostra esta correlação (,236). Já as motivações de trabalho e turismo estão mais associadas com menor vontade de realizar intercambio.

Quanto a correlação entre as variáveis plataforma e turismo colaborativo, a mais alta positiva (,295) já era esperada pois demonstra que os respondentes que conhecem o turismo colaborativo conhecem também plataformas de "work exchange".

A correlação negativa entre o curso e o conhecimento sobre turismo colaborativo chama bastante atenção pois demonstra que o quanto mais perto das Ciências Sociais Aplicadas (área integrada também pelos cursos de turismo e hotelaria) menor o conhecimento da existência do turismo colaborativo.

Na análise entre área e motivação, a correlação demonstra que pessoas que optaram por trabalho e turismo como motivação, optam por trabalhar somente na sua área de formação, enquanto as pessoas que tem como motivação conhecer uma nova cultura ou estudos, trabalhariam em qualquer área que se considerassem aptos.

Como a última análise de correlação negativa temos intenção e área (-,317), onde apresenta que pessoas que possuem interesse em trabalhar em qualquer área estão mais dispostas a trabalhar via intercâmbio de "work exchange". 


\section{CONSIDERAÇÕES FINAIS}

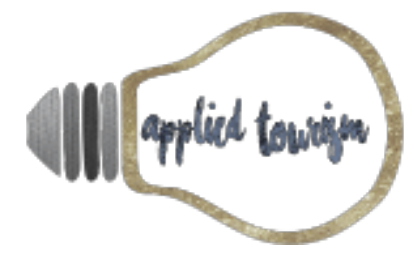

Volume 3, número 3, 2018, p. 13- 36

A curiosidade despertada sobre a temática da troca da força de trabalho pelo turismo, surgiu a partir da vivência pessoal realizada durante o estágio supervisionado no Ria Terrace Guest House em Faro, Portugal. O que me impeliu a aprofundar o conhecimento e o entendimento sobre esta modalidade de intercâmbio.

O turismo colaborativo tem como foco a economia compartilhada, onde a troca é o principal objetivo, isso permite uma redução nos custos e aumenta a possibilidades para quem utiliza essa prática.

Uma das práticas que vem crescendo é o intercâmbio via "work exchange", isso permite que pessoas possam realizar intercâmbios de forma mais barata, o que diminui uma das principais dificuldades apresentada nos resultados, que é o aspecto financeiro. Porém este tipo de intercâmbio ainda é pouco conhecido, o que demanda mais estudos sobre o assunto e também uma maior amplitude na divulgação de informações.

Os estudantes de UFPel apresentaram, em sua maioria, um grande interesse em realizar intercâmbio, e disposição para concretizar via troca de trabalho por acomodação, o que é oferecido pelas plataformas de "work exchange". O que corrobora que a falta de estudos sobre o turismo colaborativo é o que prejudica essa prática, pois se os alunos estivem mais instruídos sobre seu funcionamento, poderiam utilizar mais dessa modalidade para realizar seus interesses.

Uma das dificuldades encontradas para a realização do estudo foi a escassa literatura específica sobre o tema, sendo assim foi necessário ampliar os conceitos trabalhados para a construção do referencial teórico e a discussão dos resultados obtidos.

Outro ponto importante a ser destacado foi a utilização da rede social para divulgação do questionário, que apesar do número expressivo de participantes, retornou um número relativamente pequeno de respostas, quando observada a proporção.

Tendo em vista os resultados apresentados, concluímos que é necessário um estudo maior sobre turismo colaborativo e suas relações com o intercâmbio, a fim de possibilitar mais opções aos que tem interesse em viajar, assim como uma maior divulgação sobre o tema.

As perspectivas futuras para o tema apresentam inúmeras possibilidades de aprofundamento e expansão, o desenvolvimento deste estudo foi muito satisfatório e permitiu um maior entendimento do uso e funcionamento das plataformas work exchange e sobre o turismo colaborativo. 


\section{REFERÊNCIAS}

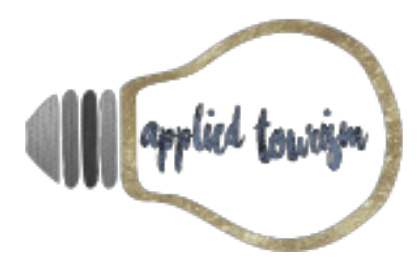

Volume 3, número 3, 2018, p. 13- 36

Arruda, A. M. T. (2004). Cultura e internacionalização: jovens brasileiros que vão residir nos EUA. Universitas: Relações Internacionais. 2 (1), 201-217.

Avital, M., Anderson, M., Nickerson, J., Sundararajan, A., Van Alstyne, M, \& Verhoeven, D. (2014). The collaborative economy: a disruptive innovation or much ado about nothing? AIS Electronic Library, 1-7.

Bandeira, R. A. de M., Marind, L. M., \& Ariotti, P. (2007). Análise da qualidade de um serviço de transporte turístico: estudo empírico da linha turismo de Porto Alegre. In: ENANPAD n. 31. XXI Encontro da Anpad, Rio de Janeiro, 1-14.

Bardin, L. (2011). Análise de conteúdo. Lisboa: Edições 70.

Bauwens, M., Mensoza, N., \& lacomella, F. (2012). A synthetic overview of the collaborative economy. Orange Labs and P2P Foundation. Recuperado em 18 julho, 2017, de https://wiki.p2pfoundation.net/Synthetic_Overview_of_the_Collaborative_Economy.

Belk R. (2014). You are what you can access: sharing and collaborative consumption online. Journal of Business Research, 67 (8), 1595-1600.

Borges, P. (2008, julho 30). Trabalhe e estude no país do Tio Sam. Correio Braziliense, pp 12.

Botsman, R. \& Rogers, R. (2011). O que é meu é seu: como o consumo colaborativo vai mudar o nosso mundo. Porto Alegre: Bookman.

Carneiro, E., Oliveira, S. A. \& Carvalho, K. D. (2010). Turismo cultural e sustentabilidade: uma relação possível? Revista Eletrônica De Turismo Cultural, 4(1).

Derdge, D., Gyimóthy, S., Birkbak, A., Jensen, T. E. \& Madsen, A. K. (2016). The impact of regulatory approaches targeting collaborative economy in the tourism accommodation sector: Barcelona, Berlin, Amsterdam and Paris. Impulse Paper, 9, 1-46.

EU Commission. (2016). A European agenda for the collaborative economy. SWD, pp 184. Recuperado 18 julho, 2017, de http://ec.europa.eu/growth/singlemarket/strategy/collaborative-economy/index_en.htm.

Fernandes, I. P. \& Coelho, M. F. (2002). Economia do turismo: teoria e prática. Rio de Janeiro: Campus.

Flick, U. (2004). Uma introdução à pesquisa qualitativa. Porto Alegre: Bookman.

Gansky, L. (2010). The Mesh: Why the Future of Business Is Sharing. New York: Penguin Group.

Giaretta, M. J. (2003). Turismo da juventude. Barueri: Manole.

Hamari, J., Sjöklint, M., \& Ukkonen, A. (2016). The sharing economy: Why people participate in collaborative consumption. Journal of the Association for Information Science and Technology, 67(9), 2047-2059.

Hennig-Thurau, T., Henning, V., \& Sattler, H. (2007). Consumer file sharing of motion pictures. Journal of Marketing, 71(4), 1-18. 


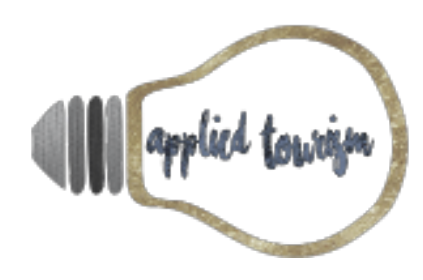

Volume 3, número 3, 2018, p. 13- 36

Lamberton, C. P., \& Rose, R. L. (2012). When is ours better than mine? A framework for understanding and altering participation in commercial sharing systems. Journal of Marketing, 76(4), 109-125.

Malhotra, N. K. (2001). Pesquisa de marketing: uma orientação aplicada. Porto Alegre: Bookman.

Moeller, S., \& Wittkowski, K. (2010). The burdens of ownership: reasons for preferring renting. Managing Service Quality: An International Journal, 20(2), 176-191.

Möhlmann, M. (2015). Collaborative consumption: determinants of satisfaction and the likelihood of using a sharing economy option again. Journal of Consumer Behaviour, 14(3), 193-207.

PWC (PriceWaterhouseCoopers). (2016) Assessing the size and presence of the collaborative economy in Europe. Recuperado em 19 julho, 2017, de http://ec.europa.eu/DocsRoom/documents/16952/attachments/1/translations/en/rend itions/native

Seiders, K., Voss, G. B., Godfrey, A. L. \& Grewal, D. (2007). SERVCON: development and validation of a multidimensional service convenience scale. Journal of the Academy of Marketing Science, 35(1), 144-156.

SLEE, T. (2013) Some obvious things about the internet reputation. Recuperado em julho 18, 2017, $d e$ http://tomslee.net/wordpress/wpcontent/uploads/2013/09/20130923_reputation_syst ems.pdf.

Stokes, K., Clarence, E., Anderson, L. \& Rinne, A. (2014). Making sense of the UK collaborative economy. Recuperado julho 20, 2017, de http://www.nesta.org.uk/publications/making-sense-uk-collaborative-economy.

Sundararajan, A. (2013). From Zipcar to the Sharing Economy. Harvard Business Review, 1. Recuperado em julho 12, 2017, de http://blogs.hbr.org/2013/01/from-zipcar-to-thesharing-eco.

Tiellet, D. L. (2008). Qualidade do serviço prestado pelas empresas de intercâmbio no programa work and travel: a percepção do participante. Trabalho de Conclusão de Curso, Universidade Federal Fluminense, Niterói, Rio de Janeiro, Brasil.

Tomazzoni, E. L., \& de Oliveira, C. C. (2013). Turismo de intercâmbio: perfis dos intercambistas, motivações e contribuições da experiência internacional. Turismo-Visão e Ação, 15(3), 388-408.

Trigo, L. G. G. (1998). A sociedade pós-industrial e o profissional em turismo. Campinas: Ed. Papirus.

Triviños, A. N. S. (1987). Introdução à pesquisa em ciências sociais. São Paulo: Ed. Atlas.

UNWTO. Why tourism? Tourism- an economic and social phenomenon. Recuperado em julho 25, 2017, de http://www2.unwto.org/content/why-tourism. 


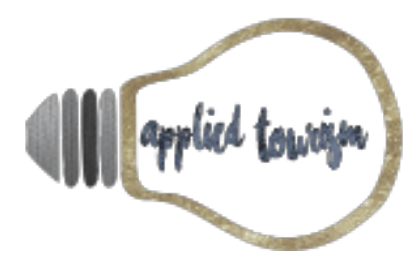

Volume 3, número 3, 2018, p. 13- 36

Uribe-Echevarria, E. (2017). Turismo colaborativo en la ciudad de Bahía Blanca. Trabalho de Conclusão de Curso, Universidad Nacional Del Sur, Bahía Blanca, Buenos Aires, Argentina.

Vergara, S. C. (2005). Métodos de pesquisa em administração. São Paulo: Ed. Atlas.

Vieira, M. P., Tres, J. \& Domingues, M. J. C. S. (2011). Fatores socioeconômicos e seus impactos na criação de programas de intercâmbio educacional em uma universidade catarinense. XI Colóquio Internacional sobre Gestão Universitária na América do Sul, Florianópolis.

Yin, R. K. (2001). Estudo de caso: planejamento e métodos. Porto Alegre: Bookman. 